\title{
Backing the Blue in the Midst of COVID-19: Simultaneous Shared Trauma and the Effects of Coping in Law Enforcement Couples
}

\author{
Jasmin Collazo ${ }^{1}$ (D) \\ Accepted: 29 November 2020 / Published online: 11 January 2021 \\ (C) The Author(s), under exclusive licence to Springer Science+Business Media, LLC part of Springer Nature 2021
}

\begin{abstract}
The impact of the novel coronavirus, also known as COVID-19, has placed a significant amount of stress on local and state law enforcement departments. In addition to responding to crimes, police officers now have additional responsibilities that include enforcing non-essential business closures, dispersing social gatherings, and maintaining order at testing sites and local hospitals, all while trying to preserve their own health. Spousal support serves a critical role in helping officers cope with occupational stressors. However, when both officer and spouse are being affected by the same traumatic event, such as the COVID-19 pandemic, this may bring additional challenges and opportunities to law enforcement couples and their mechanisms of coping. Little has been written on the effects of simultaneous shared trauma on the couple relationship. Therefore, the aim of this paper is to start a dialogue on these challenges and opportunities to serve as considerations for clinicians working with police officers and/or their spouses during and after the COVID-19 pandemic.
\end{abstract}

Keywords Police officers · Law enforcement $\cdot$ Couples $\cdot$ COVID-19 $\cdot$ Shared trauma $\cdot$ Dual trauma

\section{Introduction}

The 2019 novel coronavirus disease, also known as COVID19 , has placed a social, psychological, and economic toll on people, businesses, and government officials in the United States. Small businesses and large corporations alike have seen loss in revenue leading to permanent closures, layoffs, and furloughs (Smialek 2020). Social distancing and "shelter in place" guidelines have shifted our social communication with coworkers, family, and friends. Racial disparities come into clearer view as the coronavirus continues to disproportionately affect communities of color (Villarosa 2020). These changes, compounded with the loss of loved ones, suggests that the pandemic may have traumatic effects (Mock 2020). Although it is important to note that not everyone will experience the pandemic as a trauma, many believe that the pandemic will lead to a secondary mental health crisis (Wan 2020). As part of the response to the COVID19 pandemic, state governments are increasingly reliant on essential workers, such as healthcare professionals and first

Jasmin Collazo

Ja2589@nyu.edu

1 New York University Silver School of Social Work, 1 Washington Square North, New York, NY, USA responders, to minimize the impact of COVID-19 to their communities.

Before the coronavirus pandemic, police officers were already navigating various challenges due to the stressful nature of their jobs. Organizational stressors such as shift changes and lack of departmental support coupled with the witnessing of multiple traumatic events are risk factors that have resulted in adverse outcomes including high rates of suicide, post-traumatic stress, and work-family conflict (Hartley et al. 2013; Karaffa et al. 2015; Papazoglou 2017; Stephens et al. 1997; Violanti et al. 2019). The coronavirus pandemic has increased these risk factors as police officers now have additional responsibilities. In addition to responding to crimes, police officers must now enforce non-essential business closures, disperse social gatherings, and maintain order at testing sites and local hospitals, all while trying to preserve their own health (Sandoval 2020). Staff shortages occur as more officers call out sick or test positive for the virus, and police departments are finding the fulfillment of additional responsibilities created by the pandemic especially challenging (Bates 2020). During this crucial time, law enforcement officers may have increased need for emotional support.

Research has found that spousal support serves a critical role in helping police officers cope with traumatic incidents 
and other job stressors (Henry et al. 2011; Landers et al. 2020). However, when both the officer and their spouse are being affected by the same traumatic event, as is the case in the COVID-19 pandemic, this may introduce additional challenges and opportunities to law enforcement couples and their mechanisms of coping. Little has been written on the effects of simultaneous shared trauma on the couple relationship. Therefore, the aim of this paper is to start a dialogue on these challenges and opportunities to serve as considerations for clinicians working with police officers and/or their spouses during and after the COVID-19 pandemic.

\section{Challenges Specific to Law Enforcement Couples}

\section{Traumatic Stress}

On average, police officers are exposed to between 10 and 900 traumatic events throughout their careers (Rudofossi and Lund 2009) putting them at high risk for post-traumatic stress reactions. Oftentimes, trauma from the job spills over into their home life and police officers have difficulty leaving the stressors of work behind at the end of their shift (Karaffa et al. 2015; Landers et al. 2020; Meffert et al. 2014; Roberts and Levenson 2001). Moreover, there is some research that suggests that law enforcement spouses are also affected via secondary traumatic stress. Secondary traumatic stress is the experiencing of similar symptoms, usually to a lesser degree, of Post-Traumatic Stress Disorder [PTSD], and is experienced by having a close empathic relationship with a trauma survivor (Figley 1995; Meffert et al. 2014). In a qualitative study of eight police officers and their nonlaw enforcement spouses, Landers et al. (2020) found that both officer and spouse alike described a wide range of emotional responses stemming from the police officers' job-related trauma including mood changes, detachment, hypervigilance, and avoidance. Spouses were also found to exhibit constant worry for their partner (Landers et al. 2020). Although Landers et al. (2020) did not specify the specific causes of worry for the spouses, Meffert et al. (2014) discuss the effect of spousal perception of the officer's trauma. In their study of 71 police spouses measured at officer recruitment and 12 months post-graduation, Meffert et al. (2014) found a significant positive correlation between the spouse's perception of the officer's PTSD symptoms and their development of secondary traumatic stress at 12 months.

\section{Affect Dysregulation}

Other job-related stressors, in addition to trauma, may also have an effect on the dynamics between a police officer and his or her spouse. Roberts and Levenson (2001) report that general stress and exhaustion also impact emotional responses. In their mixed-methods study of 19 male police officers and their spouses, Roberts and Levenson (2001) utilized standardized measures and self-report daily logs to rate levels of stress and exhaustion in the spousal relationship. To determine levels of affect (positive or negative), the researchers also used recordings of the couples interacting with each other for 15 min and five minutes individually with the researcher. The couples were then asked to watch the recordings and rate how they were feeling at each moment using a dial ranging from extremely negative to extremely positive (Roberts and Levenson 2001). In their analysis, Roberts and Levenson (2001) discovered that high levels of stress predicted low levels of positive affect for officers and their wives, but only police officers were found to have high levels of negative affect (Roberts and Levenson 2001). However, high levels of physical exhaustion predicted high levels of positive affect in both members.

The above studies highlight some of the unique stressors that influence the relational dynamics in police officers and their spouses. The regulation of negative and positive affect is critical in coping with stress (Moskowitz 2010), and if left unattended, Patterson et al. (2012) suggests that this can lead to marital dissatisfaction. Therefore, it is important to not only understand how stress affects the emotional dynamics of the couple relationship, but also how their mechanisms of coping minimize or exacerbate these effects.

\section{Difficulties in Coping}

Lazarus and Folkman's (1984) transactional model of stress describes a problem-focused coping style as minimizing or eliminating aspects of the stressful situation through planned, confrontational actions. These actions can be adaptive (e.g. asking for support) or maladaptive (e.g. physical aggression). On the contrary, an emotional focused coping style is one aimed at removing or altering one's emotions from the situation (Lazarus and Folkman 1984). These can also be adaptive (e.g. empathizing) or maladaptive (e.g. utilizing alcohol to numb one's emotions). To cope with the stressors of daily life, many people utilize both coping styles (Lazarus and Folkman 1984) and the use of these coping styles influence positive and negative affect (Ben-Zur 2009). However, police officers undergo additional stressors related to the socialization and training processes of policing that bear influence on their mechanisms of coping.

The most recent Census of Law Enforcement Training Academies [CLETA] reports that the majority of training in police academies is scenario-based and action-oriented (Reaves and Trotter 2017). Scenario-based training has been found to be the most influential and the most remembered training for police recruits (Broomé 2011; Hundersmarck 2009). Many of these training processes involve 
the use of problem-focused methods aimed at changing or removing the stressor (Patterson 2016; Lazarus and Folkman 1984; VandenBos 2007). For example, defensive tactics such use-of-force are problem-focused methods aimed to eliminate or curb violent behavior from offenders. Police recruits are inculcated to respond in confrontational ways to a variety of stressful scenarios such that these responses become "routine." As this training becomes reinforced throughout their careers through the repetition of these prescribed responses on the job, police officers begin to overidentify with their police role resulting in the inability to "turn off" this role at home (Karaffa et al. 2015; Miller 2007).

Additionally, the socialization processes of policing poses challenges with emotion-focused coping as officers are expected to display a type of "masculinity" that views any emotional response as synonymous to weakness (Conti 2009; Farrell et al. 2018; Stoughton 2015; Velazquez and Hernandez 2019). As such, they are expected to be "warriors" while performing under extreme stress. The emotional control needed at the job also appears to spill over in the home resulting in emotional restriction or detachment (Karaffa et al. 2015; Kirschman et al. 2013; Miller 2007). Miller (2007) describes that this emotional restriction could also be reinforced through the officer's feelings of overprotection for their families. Police officers tend to shield their families from the most stressful and traumatic details of their jobs in order to minimize the family's worry (Karaffa et al. 2015; Toch 2002) and/or view home as a "safe haven" from the workplace (Miller 2007). This emotional detachment could inhibit the emotion-focused coping skills needed to increase intimacy, trust, and effective communication for law enforcement couples, in addition to the wider range of emotional responses that were previously mentioned by Landers et al. (2020).

The effects of organizational and traumatic stress on police officers appears to introduce many challenges to coping and relational dynamics. For many police couples, these stressors interrupt healthy coping functioning by increasing problem-focused coping and decreasing emotion-focused coping. This becomes problematic as a balance of these two types of coping styles are needed in healthy couples (Beehr et al. 1995). However, the above studies also suggest that this spillover from work to home can provide opportunities for the couple to solidify the intimacy and bonds of their relationship, especially since the longer couples remain in the relationship the more their coping mechanisms are similar to each other (Beehr et al. 1995). Little is known how these dynamics and coping styles are affected with the additional challenge of when both police officer and spouse are undergoing the same trauma at the same time.

\section{Dual Trauma}

The most common terms to describe two people experiencing the same trauma are shared trauma or dual trauma (Baum 2010; Nelson et al. 2002). However, these definitions vary by author, resulting in some confusion. For example, Tosone et al. (2012) described shared trauma or shared traumatic reality as the "affective, behavioral, cognitive, spiritual, and multi-modal responses that clinicians experience as a result of dual exposure to the same collective trauma as their clients" (p. 233). Baum (2010) also discusses shared trauma within the context of the client-therapist relationship but describes this term as having two distinctions in the literature: (a) a joint exposure to both client and therapist and (b) double exposure stemming from their individual roles as professionals and community citizens. Most of the literature on shared trauma between clinician and therapist focuses on a single traumatic event, such as the 9/11 terror attacks, but Baum (2010) proposes that the term should apply to communal or collective disasters.

The demarcation between dual trauma and shared trauma becomes blurred when broadening the scope of application to additional populations outside of a clinical relationship. For example, Jordan (2007) defines dual trauma, similar to the above definitions for shared trauma, as the "collective experience of occupational exposure as first responder in one's own community as well as having personal exposure as a citizen of the same community whose life has been interrupted by a trauma event such as a natural disaster" (p. 92). Jordan (2007) includes other disciplines that serve survivors of trauma, not only limited to emergency personnel. However, dual trauma has also been applied to couples in which both partners have experienced a single trauma or multiple traumas either before the partnership or during (Balcom 1996). For the purposes of this paper, the author will utilize Balcom's (1996) dual trauma.

\section{Dual Trauma Couples}

Nelson et al. (2002) have distinguished two types of dual trauma that relate to exposure. Specifically, they distinguish dual trauma couples as those who had individual traumatic exposure at different moments in their lives from simultaneous dual trauma couples who experienced the same trauma at the same time. Although the focus of this paper is to further shed light on simultaneous dual trauma couples spurred by the COVID-19 pandemic, a closer look in the literature reveals that dual trauma couples remain an 
understudied topic. Most of the literature regarding dual trauma in couples has largely focused on couples where both partners have had some trauma exposure (Balcom 1996; Phillips 2008; Ruhlmann et al. 2018; Nelson et al. 2002; Nelson Goff et al. 2014), but their sample populations either focused solely on non-simultaneous dual trauma couples or comprised of a mix. It appears only one study (Beitin and Allen 2005) describes positive and negative effects on relationship dynamics and coping patterns of dual trauma in couples that have undergone the same trauma at the same time (i.e. simultaneous). Based on these few studies, there are both challenges and moments of resiliency in these couples.

\section{Challenges}

Beitin and Allen (2005) conducted a study of the effects of the 9/11 terrorist attacks on 18 Arab American couples and found that they experienced four primary reactions within their relationship: withdrawal, anxiety, insecurity, and indifference. In their study comparing the relational effects of couples where one partner experienced individual trauma versus couples where both partners experienced dual trauma non-simultaneously, Ruhlmann et al. (2018) found that wives in dual trauma couples reported more trauma exposure than their spouses and that this was associated with more secure attachment promoting behaviors by their spouses. On the other hand, husbands reporting higher number of symptoms of PTSD was significantly associated with a low level of relationship satisfaction in both partners.

In her clinical observations of non-simultaneous dual trauma couples, Nelson et al. (2002) discovered six relational trauma dynamics: (1) issues of power and control; (2) competition of trauma experiences between partners; (3) external boundary ambiguities; (4) trauma-related symptoms; (5) survivor's guilt; and (6) the presence of preoccupied-dismissing interactional patterns. Balcom (1996) also describes similar dynamics in non-simultaneous dual trauma couples, such as boundary ambiguity, but adds that the most common characteristic is "intense emotional reactivity" described as "flat, lifeless affect" in couples (p. 435). In their qualitative study comparing single versus dual trauma military couples who have experienced deployment and other traumas, Nelson Goff et al. (2014) found that communication problems and experience of trauma triggers were unique to dual trauma military couples.

\section{Resiliency}

Only a few studies have highlighted the positive effects and opportunities of resiliency from dual trauma that are important to note here. Ruhlmann et al. (2018) state that the "shared experience of trauma could in fact serve to strengthen interpersonal bonds" (p. 33). Sharing the same experience allows an ability for each partner to relate to each other, allowing for higher degrees of empathy resulting in a more responsive and engaged relationship (Ruhlmann et al. 2018). Similarly, in their study, Beiten and Allen (2005) found that communication about emotional and physical effects of stress, amongst other coping mechanisms such as religion and resilience from previous trauma exposure, were found to be beneficial to coping.

Although there are no studies focused on simultaneous and non-simultaneous dual trauma in law enforcement couples, the above descriptions are intended to increase awareness and provide a foundation of potential positive and negative interpersonal dynamics that can occur in law enforcement couples who are experiencing simultaneous dual trauma stemming from the COVID-19 pandemic.

\section{Clinical Implications}

Clinicians working with spouses and law enforcement couples during and after the COVID-19 pandemic should consider how the compounded effects of occupational stressors in law enforcement and the shared trauma of the pandemic influence the relationship dynamics and coping mechanisms of these couples. For example, the pandemic has led to increased shiftwork and mandated overtime for healthy police officers due to the extra responsibilities and staff shortages (Barr 2020; Blankstein and Leonard 2020) resulting in less time spent at home. This could intensify some of the previously described reactions of anxiety, emotional detachment, low positive affect, low relationship satisfaction and thus the potential for inhibited relational intimacy. However, as suggested by Ruhlmann et al. (2018), shared trauma could be a window of opportunity for clinicians to assist couples to increase their emotional intimacy by helping them relate to one another and developing more empathic communication.

Law enforcement spouses may not witness the vast array of traumatic incidents that police officers experience on the job, but the simultaneous dual trauma of COVID-19 brings a unique opportunity for couples to remember and mourn the impact, losses, and transitions that the pandemic has brought all around them. Since the impact of COVID-19 can be seen in almost all facets of life, it is also crucial for clinicians to help law enforcement couples maintain healthy internal boundaries. Police officers may still want to maintain a sense that home is their safe haven. Therefore, clinicians could help law enforcement couples develop that balance between taking the time to communicate about the trauma while also engaging in non-trauma related talk and activities that will help the couple feel a sense of normalcy. This can also set the groundwork for the development of healthy external 
boundaries to combat some of the external boundary ambiguity found in dual trauma couples (Nelson et al. 2002).

It is also equally imperative to explore and identify the right balance of coping styles based on the relational needs in the law enforcement couple relationship. In a sample of 177 police officers and their spouses, Beehr et al. (1995) found that most police officers utilized problem-focused coping to manage job-related stressors including job assignment and somatic complaints. Although problem-focused coping has been found to be helpful in the police officer role (Rodrigues et al. 2017), Beehr et al. (1995) found that problem-focused coping in the spousal relationship was significantly associated with the perceived potential to divorce. On the other hand, relying solely on either problem-focused or emotion-focused coping of the same stressors also led to a perceived high divorce potential for the spouses (Beehr et al.1995). Only a mixture of emotion-focused and problem-focused coping reduced this likelihood for the spouses, while only emotion-focused coping reduced this perceived potential for the officers (Beehr et al. 1995).

On the other hand, a few studies describe the benefit of emotion-focused coping in law enforcement couples, specifically the use of emotional expression. In their study of 82 police officers and 89 police spouses, Karaffa et al. (2015) found that although there was high perceived conflict, $85.4 \%$ of police spouses and $84.3 \%$ of officers agreed that they were able to discuss problems with their significant other about work stress. Similarly, in their qualitative study of eight law enforcement couples, Landers et al. (2020) found that communication, especially around a traumatic event, was crucial to coping. This solidifies other findings conducted with civilian couples such as Henry et al. (2011) who conducted a qualitative study with 17 participants in relationships where one or both partners had a history of trauma exposure. Eleven of the 17 participants identified receiving emotional support from their partner, particularly "talking it out" with them, as beneficial when presented with challenges related to past trauma exposure (Henry et al. 2011). Clinicians must also be mindful that the impact of the coronavirus is constantly fluctuating and the coping styles utilized throughout should frequently be revisited in treatment.

Lastly, a common theme in law enforcement couples and shared trauma couples is a low level of relationship satisfaction during periods of high stress (Nelson Goff et al. 2014; Roberts and Levenson 2001; Ruhlmann et al. 2018). The COVID-19 pandemic may exacerbate these challenges as couples spend less time with each other, amounting to a decrease in physical and emotional support. Thus, it is important for law enforcement couples to restore aspects of normalcy, even during a time where they are spending less time together. Phillips (2008) describes that couples respond positively when connecting with positive memories of the past, such as when the couple first met. It could also be helpful for couples to describe some positive activities that they were engaging in before the changes brought on by the pandemic. Guiding couples towards this imagery and sensation can serve as a catalyst to be more intentional with the time they are able to spend with each other during and post-pandemic.

\section{Conclusion}

The novel coronavirus pandemic has made a significant social, emotional, economic, and psychological impact that has pervaded almost every facet of life. In response to this impact, police officers have had to bear increased responsibilities and consequentially, increased stress on the job. Spousal support can assist with the physical and emotional burden of the job; however, the simultaneous dual trauma of the COVID-19 pandemic can bring additional challenges to relational dynamics and mechanisms of coping in the spousal relationship. Unfortunately, law enforcement couples remain an understudied population (Karaffa et al. 2015), with no research published on simultaneous and non-simultaneous dual trauma in this population. Future directions for research should focus on these experiences, including how relational dynamics and coping mechanisms are affected by simultaneous dual trauma with or without previous trauma exposure in one or both partners.

Another limitation is that most of the current research focuses on male police officers and their females spouses with little focus on same-sex couples. With the exception of Landers et al. (2020), many studies also do not describe the occupational status of the spouse and the author wonders about the unique experiences of shared trauma where both partners are in law enforcement. Future directions for research should also include these populations. It is also important to discover the unique challenges and coping mechanisms of law enforcement couples compared to couples where one or both partners are in other first responder professions. There is some research that describe similarities of the impact these professions have on the spousal relationship (see Mormon et al. 2019; Porter and Henriksen 2016; Regehr et al. 2005), however, more research is needed on the differences in coping mechanisms.

The COVID-19 pandemic presents a unique opportunity to study the lived experiences of law enforcement couples experiencing simultaneous dual trauma. Similarly, the pandemic also provides the opportunity to study the shared resilience (Nuttman-Schwartz 2015) in these couples. Much is still yet to be learned on the impact of COVID-19 and the above clinical implications are intended to be a starting point. Clinicians working with law enforcement couples are encouraged to contribute to the literature by sharing case studies and observations of their work as this could enhance 
treatment with this population. Although the above treatment considerations and implications cannot be generalized to all law enforcement couples with simultaneous dual trauma, the author hopes that this work sparks an ongoing dialogue in this important area of clinical treatment and research.

\section{Compliance with Ethical Standards}

Conflict of interest The author declares that the author has no conflict of interest.

\section{References}

Balcom, D. (1996). The interpersonal dynamics and treatment of dual trauma couples. Journal of Marital and Family Therapy, 22(4), 431-442. https://doi.org/10.1111/j.1752-0606.1996.tb00218.x.

Barr, L. (2020, March 14). No days off for police departments during coronavirus outbreak. ABC News. Retrieved from https://abcne ws.go.com/Health/days-off-police-departments-coronavirus-outbr eak/story?id $=69583481$

Bates, J. (2020, April 2). Police departments, sheriffs' offices across the U.S. grapy with COVID- 19's impact on public safety-and their own. Time Magazine. Retrieved from https://time.com/5812833/ coronavirus-police-departments/.

Baum, N. (2010). Shared traumatic reality in communal disasters. Psychotherapy: Theory, Research, Practice, Training, 47(2), 249-259. https://doi.org/10.1037/a0019784.

Beehr, T. A., Johnson, L. B., \& Nieva, R. (1995). Occupational stress: Coping of police and their spouses. Journal of Organizational Behavior, 16(1), 3-25.

Beitin, B. K., \& Allen, K. R. (2005). Resilience in Arab American couples after September 11, 2001: A systems perspective. Journal of Marital and Family Therapy, 31(3), 251-267. https://doi. org/10.1111/j.1752-0606.2005.tb01567.x.

Ben-Zur, H. (2009). Coping styles and affect. International Journal of Stress Management, 16(2), 87-101. https://doi.org/10.1037/ a0015731.

Blankstein, A. \& Leonard, E. (2020, March 21). L.A. police could start 12-hour shifts, raising COVID-19 among rank and file. NBC News. Retrieved from https://www.nbcnews.com/news/us-news/1police-could-start-12-hour-shifts-raising-covid-19-n1165831

Broomé, R. E. (2011). An empathetic psychological perspective of police deadly force training. Journal of Phenomenological Psychology, 42(2), 137-156. https://doi.org/10.1163/156916211X 599735.

Conti, N. (2009). A visigoth system. Journal of Contemporary Ethnography, 38(3), 409-432. https://doi.org/10.1177/0891241608 330092.

Farrell, A., Monk-Turner, E., Danner, M., \& Scallon, C. (2018). "There's no crying in police work:" Exploring police shootings with feminist methods. Gender Issues, 35(3), 220-235. https:// doi.org/10.1007/s12147-017-9198-5.

Figley, C. R. (1995). Compassion fatigue: Coping with secondary traumatic stress disorder in those who treat the traumatized. New York: Brunner/Mazel.

Hartley, T. A., Violanti, J. M., Sarkisian, K., Andrew, M. E., \& Burchfiel, C. M. (2013). PTSD symptoms among police officers: Associations with frequency, recency, and types of traumatic events. International Journal of Emergency Mental Health, 15(4), 241-253.
Henry, S. B., Smith, D. B., Archuleta, K. L., Sanders-Hahs, E., Goff, B. S. N., Reisbig, A. M. J., et al. (2011). Trauma and couples: Mechanisms in dyadic functioning. Journal of Marital and Family Therapy, 37(3), 319-332. https://doi.org/10.111 1/j.1752-0606.2010.00203.x.

Hundersmarck, S. (2009). Police recruit training: Facilitating learning between the academy and field training. The FBI Law Enforcement Bulletin, 78, 26. Retrieved from https://search.proquest.com/ docview/204189522

Jordan, K. (2007). A case study: Factors to consider when doing 1:1 crisis counseling with local first responders with dual trauma after hurricane Katrina. Brief Treatment and Crisis Intervention, 7(2), 91-101. https://doi.org/10.1093/brief-treatment/mhm001.

Karaffa, K., Openshaw, L., Koch, J., Clark, H., Harr, C., \& Stewart, C. (2015). Perceived impact of police work on marital relationships. The Family Journal, 23(2), 120-131. https://doi. org/10.1177/1066480714564381.

Kirschman, E., Kamena, M., \& Fay, J. (2013). Counseling cops: What clinicians need to know. New York, NY: The Guilford Press.

Landers, A. L., Dimitropoulos, G., Mendenhall, T. J., Kennedy, A., \& Zemanek, L. (2020). Backing the blue: Trauma in law enforcement spouses and couples. Family Relations, 69(2), 308-319. https://doi.org/10.1111/fare.12393.

Lazarus, R. S., \& Folkman, S. (1984). Stress, appraisal and coping. New York: Springer.

Meffert, S. M., Henn-Haase, C., Metzler, T. J., Qian, M., Best, S., Hirschfeld, A., et al. (2014). Prospective study of police officer spouse/partners: A new pathway to secondary trauma and relationship violence? PLOS ONE, 9(7), e100663. https://doi.org/10.1371/ journal.pone.0100663.

Miller, L. (2007). Police families: Stresses, syndromes, and solutions. The American Journal of Family Therapy, 35(1), 21-40. https:// doi.org/10.1080/01926180600698541.

Mock, J. (2020, June 1). Psychological trauma is the next crisis for coronavirus health workers. Scientific American. Retrieved from https://www.scientificamerican.com/article/psychological-traum a-is-the-next-crisis-for-coronavirus-health-workers1/

Morman, M. T., Schrodt, P., \& Adamson, A. (2019). Firefighters' job stress and the (un)intended consequences of relational quality with spouses and firefighter friends. Journal of Social and Personal Relationships, 37(4), 026540751988635-1113. https://doi. org/10.1177/0265407519886355.

Moskowitz, J. T. (2010). Coping interventions and the regulation of positive affect. In S. Folkman (Ed.), The Oxford handbook of stress, health, and coping (pp. 407-427). New York: Oxford University Press.

Nelson, B. S., Wangsgaard, S., Yorgason, J., Kessler, M. H., \& Carter-Vassol, E. (2002). Single- and dual-trauma couples. American Journal of Orthopsychiatry, 72(1), 58-69. https://doi. org/10.1037/0002-9432.72.1.58.

Nelson Goff, B. S., Irwin, L., Cox, M., Devine, S., Summers, K., \& Schmitz, A. (2014). A qualitative study of single-trauma and dual-trauma military couples. Psychological Trauma: Theory, Research, Practice, and Policy, 6(3), 216-223. https://doi. org/10.1037/a0036697.

Nuttman-Shwartz, O. (2015). Shared resilience in a traumatic reality. Trauma, Violence \& Abuse, 16(4), 466-475. https://doi. org/10.1177/1524838014557287.

Papazoglou, K. (2017). Examining the psychophysiological efficacy of CBT treatment for first responders diagnosed with PTSD: An understudied topic. SAGE Open, 7(3), 215824401772940. https ://doi.org/10.1177/2158244017729407.

Patterson, G. (2016). A brief exploratory report of coping strategies among police recruits during academy training. Psychological Reports, 119(2), 557-567. https://doi.org/10.1177/0033294116 662685. 
Patterson, J., Gardner, B., Burr, B., Hubler, D., \& Roberts, K. (2012). Nonverbal behavioral indicators of negative affect in couple interaction. Contemporary Family Therapy, 34(1), 11-28. https://doi. org/10.1007/s 10591-011-9170-6.

Phillips, S. B. (2008). Two's company, three's not a crowd: A relational approach to couple intervention after trauma. Group, 32(3), 191-208. Retrieved from https://www.jstor.org/stable/41719200

Porter, K. L., \& Henriksen, R. C. (2016). The phenomenological experience of first responder spouses. The Family Journal, 24(1), 44-51. https://doi.org/10.1177/1066480715615651.

VandenBos, G. R. (Ed.). (2007). APA dictionary of psychology. Washington DC: American Psychological Association.

Ruhlmann, L. M., Gallus, K. L., \& Durtschi, J. A. (2018). Exploring relationship satisfaction and attachment behaviors in single- and dual-trauma couples: A pilot study. Traumatology, 24(1), 27-35. https://doi.org/10.1037/trm0000129.

Reaves, B. A., \& Trotter, A. L. (2017). The state of law enforcement training academies. Sheriff \& Deputy, 69(1), 44-47. Retrieved from http://proxy.library.nyu.edu/login?url=http://search.ebsco host.com/login .asp $\mathrm{x}$ ?direct $\mathrm{t}=$ true $\& \mathrm{db}=\mathrm{i} 3 \mathrm{~h} \& \mathrm{AN}=12082$ 4305\&site $=$ eds-live

Regehr, C., Dimitropoulos, G., Bright, E., George, S., \& Henderson, J. (2005). Behind the brotherhood: Rewards and challenges for wives of firefighters. Family Relations, 54(3), 423-435. https:// doi.org/10.1111/j.1741-3729.2005.00328.x.

Rodrigues, S., Kaiseler, M., Cristina Queirós, \& Miguel Basto-Pereira. (2017). Daily stress and coping among emergency response officers: A case study. Emerald Publishing Limited. https://doi. org/10.1108/IJES-10-2016-0019

Roberts, N. A., \& Levenson, R. W. (2001). The remains of the workday: Impact of job stress and exhaustion on marital interaction in police couples. Journal of Marriage and Family, 63(4), 1052-1067.

Rudofossi, D., \& Lund, D. A. (2009). A cop doc's guide to public safety complex trauma syndrome : Using five police personality styles. Amityville: Routledge. Retrieved from http://ebookcentral.proqu est.com/lib/nyulibrary-ebooks/detail.action?docID $=3117903$

Sandoval, E. (2020, April 14). New role for New York police: Breaking up crowds at Trader Joe's. The New York Times. Retrieved from https://www.nytimes.com/2020/04/14/nyregion/coronaviru s-nypd-social-distancing.html.

Smialek, J. (2020, May 13). Fed chair Powell says economy may need more government support. The New York Times. Retrieved from https://www.nytimes.com/2020/05/13/business/economy/fed-chair -powell-economy-virus-support.html.
Stephens, C., Long, N., \& Miller, I. (1997). The impact of trauma and social support on posttraumatic stress disorder: A study of new zealand police officers.https://doi.org/10.1016/S0047 -2352(97)00015-9

Stoughton, S. (2015). Law enforcement's "warrior" problem. Harvard Law Review, 128(6), 225-234. Retrieved from http://proxy .library.nyu.edu/login?url=http://search.ebscohost.com/login .aspx ?direct $=$ true $\& \mathrm{db}=\mathrm{bth} \& \mathrm{AN}=102118334 \&$ site $=$ eds-live

Toch, H. (2002). Stress in policing. Washington, DC: American Psychological Association.

Velazquez, E., \& Hernandez, M. (2019). Effects of police officer exposure to traumatic experiences and recognizing the stigma associated with police officer mental health. Policing: An International Journal, 42(4), 711-724. https://doi.org/10.1108/PIJPS M-09-2018-0147.

Tosone, C., Nuttman-Shwartz, O., \& Stephens, T. (2012). Shared trauma: When the professional is personal. Clinical Social Work Journal, 40(2), 231-239. https://doi.org/10.1007/s1061 5-012-0395-0.

Villarosa, L. (2020, April 29). 'A terrible price': The deadly racial disparities of Covid-19 in America. The New York Times Magazine. Retrieved from https://www.nytimes.com/2020/04/29/magazine/ racial-disparities-covid-19.html.

Violanti, J. M., Owens, S., McCanlies, E., Fekedulegn, D., \& Andrew, M. E. (2019). Law enforcement suicide: A review. Policing: An International Journal, 42(2), 141-164. https://doi.org/10.1108/ pijpsm-05-2017-0061.

Wan, W. (2020, May 4). The coronavirus pandemic is pushing America into a mental health crisis. The Washington Post. Retrieved from https://www.washingtonpost.com/health/2020/05/04/mental-healt h-coronavirus/.

Publisher's Note Springer Nature remains neutral with regard to jurisdictional claims in published maps and institutional affiliations.

Jasmin Collazo is a Licensed Clinical Social Worker working with young adults in a community-based setting. Jasmin also works with local police departments to develop trainings surrounding mental health and trauma-informed community policing. This work has become the main focus of her Doctor of Social Welfare studies at New York University. 